Document downloaded from:

http://hdl.handle.net/10251/122919

This paper must be cited as:

Benajes, J.; Novella Rosa, R.; Pastor Enguídanos, JM.; Hernández-López, A.; Kokjohn, SL. (2018). Computational optimization of the combustion system of a heavy duty direct injection diesel engine operating with dimethyl-ether. Fuel. 218:127-139.

https://doi.org/10.1016/j.fuel.2018.01.020

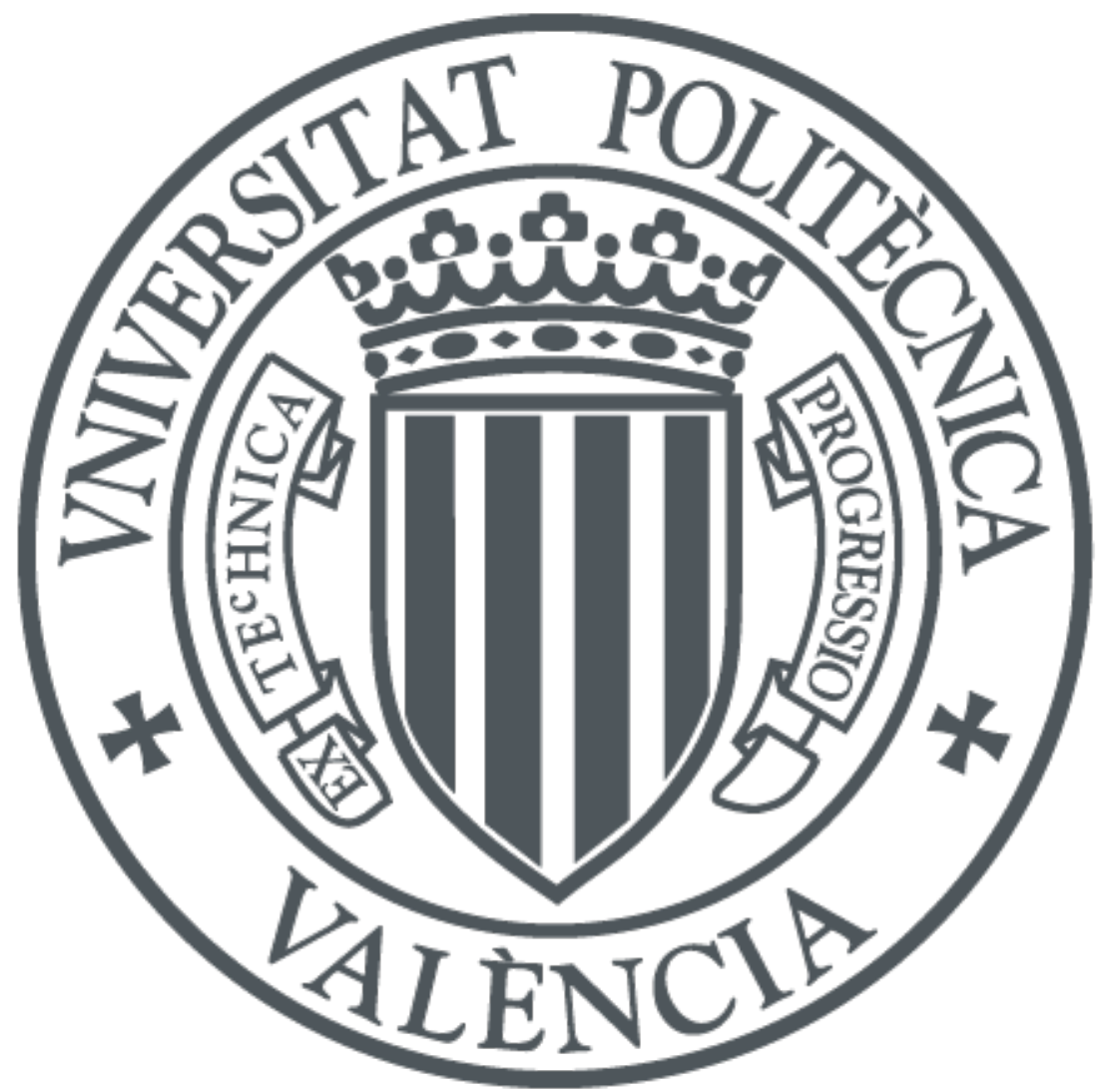

The final publication is available at

https://doi.org/10.1016/j.fuel.2018.01.020

Copyright Elsevier

Additional Information 


\title{
Computational Optimization of the Combustion System of a Heavy Duty Direct Injection Diesel Engine Operating with Dimethyl-Ether
}

\author{
Jesús Benajes, Ricardo Novella, Jose Manuel Pastor, Alberto Hernández-López \\ CMT-Motores Térmicos \\ Universitat Politècnica de València \\ Camino de Vera $s / n, 46022$, Valencia (Spain) \\ Sage L. Kokjohn \\ Engine Research Center, Department of Mechanical Engineering \\ University of Wisconsin-Madison \\ 111 Engineering Research Bldg, 1500 Engineering Drive, Madison, WI 53706 (USA)
}

\begin{abstract}
A genetic algorithm optimization methodology is applied to the design of the combustion system of a heavy-duty diesel engine fueled with dimethyl ether (DME). The optimization includes the key combustion system related hardware, bowl geometry and injection nozzle design, together with the most relevant air management and injection settings. The GA was linked to the KIVA computational fluid dynamics code and an automated grid generation tool to perform a singleobjective optimization. The optimization target focused on maximizing efficiency, while keeping NOx emissions, peak pressure and maximum pressure rise rate under the baseline engine levels. This research work not only provides the optimum combustion system definition, but also the cause-effect relation between the inputs and outputs under investigation, identifying the most relevant parameters controlling the performance of a DME fueled engine. Piston bowl geometry is found to primarily influence heat transfer and combustion efficiency due to its impact on the surface area and fuel distribution, respectively. Mixing is most affected by the injection system parameters. Finally, the optimum DME engine configuration provides $6.9 \%$ absolute net indicated efficiency improvement over the baseline engine fueled with DME. This study confirms the potential of DME as a promising fuel for the future generation of compression ignition engines and demonstrates the need to co-optimize the fuel and combustion system.
\end{abstract}

Keywords:

Dimethyl Ether, Alternative Fuels, Pollutant Emissions, Engine Efficiency, Engine Optimization 


\section{Definition of Acronyms}

\begin{tabular}{|c|c|}
\hline ATDC & After Top Dead Center \\
\hline CFD & Computational fluid dynamics \\
\hline $\mathrm{CO}$ & Carbon monoxide \\
\hline COSSO & Component Selection and Smoothing Operator \\
\hline DME & Dimethyl ether \\
\hline Dnoz & Nozzle hole diameter \\
\hline dS & Cell size \\
\hline EGR & Exhaust gas recirculation \\
\hline $\mathrm{ERC}$ & Engine Research Center \\
\hline EVO & Exhaust valve opening \\
\hline GA & Genetic algorithm \\
\hline $\mathrm{HCCI}$ & Homogenous charge compression ignition \\
\hline HD & Heavy Duty \\
\hline HRR & Heat release rate \\
\hline IMEP & Gross indicated mean effective pressure \\
\hline IP & Injection pressure \\
\hline IVC & Intake valve closure \\
\hline $\mathrm{KH}$ & Kelvin Helmholtz \\
\hline LDEF & Lagrangian-Drop and Eulerian-Fluid \\
\hline $\operatorname{maxPRR}$ & Maximum pressure rise rate \\
\hline NA & Nozzle angle \\
\hline NIE & Net indicated efficiency \\
\hline NSGAII & Non-dominated sorting genetic algorithm \\
\hline PIVC & Pressure at IVC \\
\hline PP & Peak cylinder pressure \\
\hline RCCI & Reactivity Controlled Compression Ignition \\
\hline RSM & Root-mean-square \\
\hline RT & Rayleigh Taylor \\
\hline SCR & Selective catalytic reduction \\
\hline SOI & Start of injection \\
\hline $\mathrm{UHC}$ & Unburned hydrocarbons \\
\hline WSR & Well Stirred Reactor \\
\hline
\end{tabular}




\section{Introduction}

In recent years, a substantial effort has focused on enabling high efficiency and low emissions using advanced combustion. For example, Dec [1] demonstrated high efficiency and low NOx and soot emissions across a wide range of conditions using gasoline homogenous charge compression ignition (HCCI) combustion. The results are promising, but controlling HCCI combustion, especially at high engine loads, is challenging. Other advanced combustion concepts have been presented that aid in combustion phasing control. For example, Kokjohn et al. [2] proposed blending two fuels inside the combustion chamber to simultaneously control combustion phasing and the rate of heat release. While these results are interesting, the use of two fuels is not practical in some applications.

An alternative approach to enable high efficiency and low emissions is to take advantage of fuel properties that have the potential to improve emissions and efficiency tradeoffs. One fuel that has the potential to improve efficiency and emissions tradeoffs is Di-methyl ether (DME). DME forms little to no soot emissions even under stoichiometric operation [3]. This is the result of a high oxygen content (34.8\%) and lack of carbon-carbon bonds [4] [5]. Accordingly, DME removes the classic soot-NOx tradeoff, allowing the use of high levels of exhaust gas recirculation (EGR) to control engine out NOx emissions. This unique property of DME, may make it possible to improve the emissions and efficiency tradeoff, while maintaining the favorable control characteristics of mixing controlled combustion by developing an optimized DME fueled combustion system.

Previous DME engine research has shown encouraging results. Jinyoung et al. [6] focused on improving a HCCI engine fueled with DME by using direct injection and EGR. The results showed that the use of direct injection and EGR allowed gross indicated mean effective 
pressure (IMEP) to be increased by $53 \%$ over the premixed case without EGR. Hyung et al. [7] used a micro genetic algorithm coupled with KIVA-3V to optimize a diesel engine fueled with DME by modifying injection settings. This study showed that the non-sooting nature of DME has more potential to improve the NOx - efficiency tradeoff than diesel fuel. That is, by using DME, the soot-NOx tradeoff is eliminated and methods of NOx control that would result in high soot levels for diesel fuel (e.g., high EGR), can be used to maintain diesel-like efficiency at acceptable NOx levels. Su et al [8] demonstrated this using engine experiments. Park et al. [9] optimized the combustion chamber geometry and injection settings of a diesel engine fueled with DME. The results shifted from a baseline reentrant geometry to a bathtub type geometry that, together with an advanced SOI, managed to simultaneously reduce $\mathrm{NOx}, \mathrm{CO}$ and $\mathrm{HC}$ without sacrificing fuel consumption. In parallel, the same optimization with diesel fuel was performed but the emissions reduction was coupled with a deterioration in consumption, proving the benefits of the DME fuel properties. However, this work was said to have a limitation in terms of computational resources forcing the study to use a micro genetic algorithm limiting the population to 5 and reducing the amount of inputs variables. For that reason the geometry generation tool was limited to 5 inputs punishing the flexibility to generate a wide diversity of reentrant geometries and the settings optimized also avoided key parameters such as swirl ratio or nozzle hole diameter when optimizing performance and emissions. For that reason the present paper uses a new methodology with a single objective genetic algorithm, taking into account more inputs to increase the flexibility and focusing on improving efficiency while keeping emissions under control.

Due to the previously discussed differences between DME and diesel fuel in terms of combustion and emissions, it is likely that the optimum combustion chamber for a DME fueled 
engine would be different from the combustion chamber optimized for a diesel fueled engine. The design of the combustion chamber geometry of CI engines has a significant impact on the combustion process and is critical to control pollutant emissions, while maintaining competitive efficiency levels. Thus, a large-scale optimization of the combustion chamber and the injection nozzle designs coupled with a set of the most relevant air management and injection settings is needed to understand the potential of DME fueled CI combustion systems. Due to the high computational cost of combustion system optimization, evolutionary optimization methods (e.g., genetic algorithms) are of great interest [10] [11] [12] [13].

The main objective of the present research is the optimization of the combustion system for a Heavy Duty (HD) compression ignition engine fueled with DME including the piston bowl and nozzle matching, air management, and injection schedule. The optimization is performed using an in-house computational fluid dynamics (CFD) code coupled with a genetic algorithm (GA) and an automatic mesh generator. A total of 2 injection settings (start of injection (SOI), injection pressure (IP)), 3 air management settings (EGR, pressure at IVC (PIVC), swirl), 15 bowl geometry and 2 nozzle design parameters (nozzle hole diameter (dnoz), nozzle angle (NA)) are simultaneously optimized in order to find the best combustion system considering engine efficiency as the target and emissions and thermomechanical stresses as constraints.

\section{Tools and Methodology}

\subsection{Engine Specifications}

The engine modeled is a single cylinder version of a Caterpillar C-15, 15-L six-cylinder engine. Table 1 shows the engine and injector specifications. The C-15 is typical of a heavy-duty size-class diesel engine with a bore of $137 \mathrm{~mm}$ and a stroke of $171 \mathrm{~mm}$ yielding a displacement of 2.5 liters per cylinder. 
Table 1 - Engine and Injector Specifications.

\begin{tabular}{|l|l|}
\hline Engine Specifications & 2.5 \\
\hline Displacement [L/cylinder] & 137 x 171 \\
\hline Bore x Stroke [mm] & $17: 1$ \\
\hline Compression Ratio [-] & 0.7 \\
\hline Swirl Ratio [-] & -154 \\
\hline IVC [deg aTDC] & 113 \\
\hline EVO [ deg aTDC] & 6 \\
\hline Fuel Injector & 0.214 \\
\hline Number of Holes & 130 \\
\hline Hole Diameter [mm] & \multicolumn{2}{|l|}{} \\
\hline Included Spray Angle[deg] &
\end{tabular}

\subsection{Operating Conditions}

The engine was operated at $1800 \mathrm{rev} / \mathrm{min}$ and a nominal load of 18 bar gross IMEP (i.e., near the rated power condition). For the validation tests carried out using diesel fuel, the fueling was held constant and the SOI timing was swept from $-18^{\circ}$ to $-3^{\circ}$ aTDC. The EGR rate, intake pressure, and intake temperature were held constant at $25 \%, 3.1 \mathrm{bar}$, and $60^{\circ} \mathrm{C}$, respectively. Details of the operating condition and its related settings are included in Table 2.

Table 2 - Operating conditions

\begin{tabular}{|l|l|}
\hline Nominal gross IMEP $[\mathrm{bar}]$ & 18 \\
\hline Speed $[$ rev/min] & 1800 \\
\hline Intake Temperature $\left[{ }^{\circ} \mathrm{C}\right]$ & 60 \\
\hline Coolant Temperature $\left[{ }^{\circ} \mathrm{C}\right]$ & 80 \\
\hline EGR Temperature $\left[{ }^{\circ} \mathrm{C}\right]$ & 60 \\
\hline Intake Pressure $[\mathrm{bar}]$ & 3.1 \\
\hline SOI Timing - command $[\mathrm{deg}$ aTDC] & -18 to -3 \\
\hline Fuel Mass $[\mathrm{mg} /$ cycle] & 252 \\
\hline EGR Rate $[\%]$ & 25 \\
\hline Motored Temperature at TDC $[\mathrm{K}]$ & 1018 \\
\hline Motored Pressure at TDC $[\mathrm{bar}]$ & 147 \\
\hline Injection Pressure $[\mathrm{bar}]$ & 1800 \\
\hline
\end{tabular}




\subsection{Computational Approach}

Computations were performed using an in-house CFD code based on the KIVA-3v release 2 platform [14] with improvements to many physical and chemistry models developed at the Engine Research Center (ERC) [15], [16], [17]. To reduce computation time, simulations consider a sector of the combustion chamber representing a single nozzle hole of the six hole fuel injector. Additionally, the simulations are restricted to the closed engine cycle, from intake valve closure (IVC) to exhaust valve opening (EVO). The simulations were initialized using solid body rotation to specify the azimuthal velocity flow field at IVC. This section provides an overview of the physical models important to the present study.

\subsubsection{Combustion Model}

The KIVA-3v code is coupled with the SpeedCHEM [18] solver for detailed chemistry calculations. The RNG k- $\varepsilon$ model [19] is used for the turbulence calculations; however, sub-grid turbulence-chemistry interactions are not considered. That is, the current implementation of the SpeedCHEM solver considers every computational cell to be a Well Stirred Reactor (WSR) and the cell average species production rates are assumed to be equal to the species production rates evaluated at the average cell conditions. At each time step, species concentrations and thermodynamic conditions are passed to the chemistry solver for each computational cell. The chemistry solver then integrates the mass and energy equations at constant volume over a period of time equal to the computational time step. Although sub-grid scale turbulent-chemistry interactions are not considered, by coupling the chemistry solver with the CFD code, the effects of turbulence on combustion are accounted by modeling the effects of turbulence on property transport, heat flux, and mixture formation. Justification for this modeling approach has also been discussed by Kokjohn and Reitz [20]. 
The chemistry of DME was simulated using a reduced reaction mechanism for DME consisting of 29 species and 66 reactions [21]. Validation simulations of conventional diesel combustion were carried out using n-heptane as surrogate and describing its oxidation by a reduced reaction mechanism made up of 45 species and 142 reactions [16].

\subsubsection{Spray Model}

The spray model employed in this study uses the Lagrangian-Drop and Eulerian-Fluid (LDEF) approach. Because a detailed chemistry model is used, it is desirable to use a relatively coarse computational mesh; however, severe grid size dependency has been observed in LDEF spray models. The problem is most severe in the near nozzle region where the droplets are very close together and occupy only small portions of the Eulerian mesh cell. Abraham [22] showed that accurate modeling of the near nozzle region required grid resolution on the order of the orifice diameter. However, it is not feasible from a computational time standpoint to solve GA engine optimization problems on such a fine mesh. Furthermore, a fundamental assumption of the LDEF approach is that the volume fraction of droplets in each cell is small, that is, the void fraction is near unity. This assumption may be violated if the mesh size is overly refined up to a mesh size of the order of the droplet size. In order to reduce the grid size dependency of the LDEF spray model and allow accurate spray simulation on a relatively coarse grid, the Gasjet model of Abani et al. [17] [23] is employed to model the relative velocity between the droplets and gas phase in the near nozzle region. Their approach assumes that the relative velocity between a given droplet and its surrounding gas phase is equal to that between the droplet and a turbulent gas jet with the same mass and momentum flux of that of the injected fuel spray. This approach imposes an axial component for the gas phase velocity as a function of distance from the nozzle, which is used in the droplet acceleration equation given by 


$$
\frac{d U}{d t}=\frac{3}{8} C_{D} \frac{\rho_{g}}{\rho_{l} r_{d}}\left|U-V_{g a s}\right|\left(U-V_{g a s}\right)
$$

where $U$ is the droplet velocity vector, $C_{D}$ is the droplet drag coefficient, which is a function of Reynolds number, $\rho_{g}$ and $\rho_{l}$ are the gas and liquid phase densities, respectively, $r_{d}$ is the droplet radius, and $V_{g a s}$ is the gas phase velocity vector given as $V_{g a s}=\left(V_{x}, V_{y}, V_{z}\right)$. The velocity components perpendicular to the spray axis (i.e., $V_{y}$ and $V_{z}$ ) are obtained from the Eulerian gas phase solution and $V_{x}$, the axial component of the gas phase velocity, is found from gas-jet theory as

$$
V_{x}=\min \left[U_{i n j}, \frac{3 U_{i n j} d_{n o z} \sqrt{\frac{\rho_{l}}{\rho_{g}}}}{K_{e n t r} x}\left(\frac{1}{\left(1+\frac{12 r^{2}}{K_{e n t r}^{2} x^{2}}\right)^{2}}\right)\right]
$$

where $U_{i n j}$ is the injection velocity, $d_{n o z}$ is the nozzle diameter, $K_{e n t r}$ is a model constant taken to be 0.7 as suggested by Abani et al. [17], $x$ is the position downstream of the nozzle on the spray axis, and $r$ is the radial position.

Droplet breakup is modeled using the hybrid Kelvin Helmholtz (KH) - Rayleigh Taylor (RT) model described by Beale and Reitz [15]. The droplet collision model is based on O'Rourke's model; however, a radius of influence method is used to determine the possible collision partners to further reduce mesh dependency [24]. In addition, the collision model was expanded by Munnannur [24] to include a more comprehensive range of collision outcomes. The current implementation of the droplet collision model considers the effects of bounce, coalescence, and fragmenting and non-fragmenting separations. Droplet interactions with the 
wall are considered through a wall film submodel [25], which includes the effects associated with splash, film spreading, and motion due to inertia.

\subsubsection{Model Validation}

Experimental data for the engine fueled with DME was not available. Accordingly, the CFD code was validated by first comparing to engine data from Allen [26] where the same engine was operated at the condition of interest (18 bar IMEP and $1800 \mathrm{rev} / \mathrm{min}$ ) using diesel fuel over a range of start-of-injection timings. Next, DME fueled simulations were performed to verify that the model is able to qualitatively capture the changes in combustion characteristics expected when diesel fuel is replaced with DME (i.e., shorter ignition delay and shorter combustion duration). The justification for using this approach is

1. The operating range considered in this study is expected to be mixing controlled. Accordingly, validation using diesel fueled combustion in a mixing controlled combustion regime provides validation that the CFD model adequately captures the mixing characteristics.

2. The DME chemical kinetics mechanism and spray model has been validated in previous work (see Pan et al. [21]). The reaction mechanism has been shown to accurately capture the ignition delay from shock to data and internal combustion engines. The spray model has been shown to capture DME spray penetration accurately.

Prior to performing model validation, a grid convergence study was performed to identify the necessary grid resolution. The CFD results for axial cell sizes (dS) between $2 \mathrm{~mm}$ and $4 \mathrm{~mm}$ are shown in Figure 1. In can be seen that the effect of the cell size starts to minimize at dS $3 \mathrm{~mm}$ showing negligible differences between dS $3 \mathrm{~mm}$ and $2 \mathrm{~mm}$ in terms of NOx emissions and very little variations in terms of heat release rate (HRR) profile. Accordingly, cell sizes of $3 \mathrm{~mm}$ or 
lower were considered to generate grid independent results. The final setup used a cell size of 2 mm. The typical cell count was 30,000 to 40,000 cells at BDC, depending on the shape of the piston bowl, and each case took approximately $20 \mathrm{hr}$ to complete.
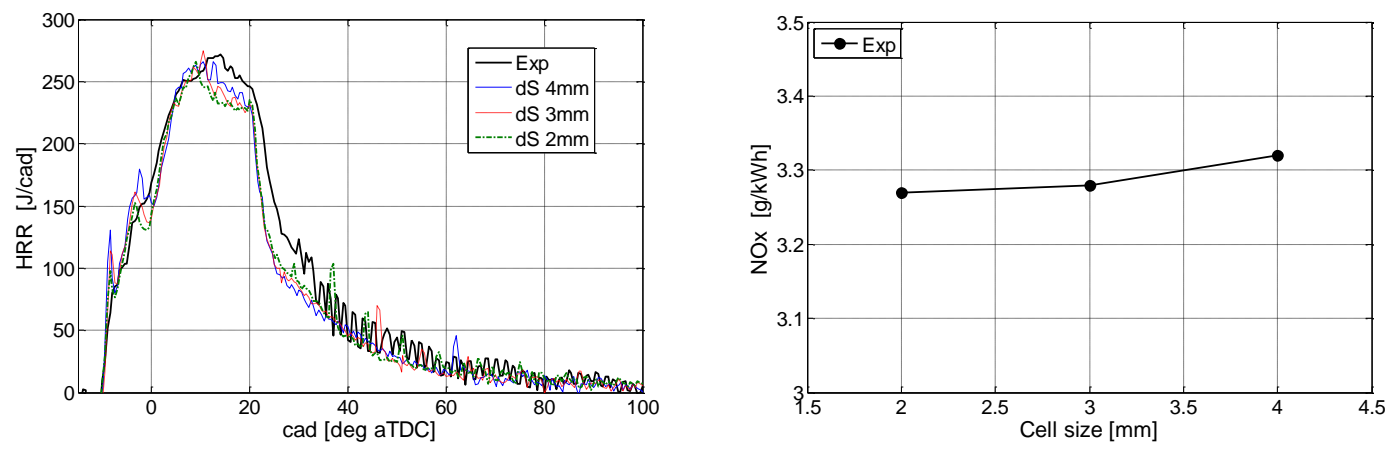

Figure 1 - Effect of cell size on (a) heat release rate (HRR) (b) NOx emissions.

Figure 2 shows the comparison between the experimental and CFD in-cylinder pressure and heat release rate profiles for the baseline diesel case with 3 different SOI values. Although several cases show a slight over prediction of the peak pressure value resulting from a more intense premixed combustion stage, in general, the simulations accurately reproduce the combustion characteristics under mixing controlled operation.

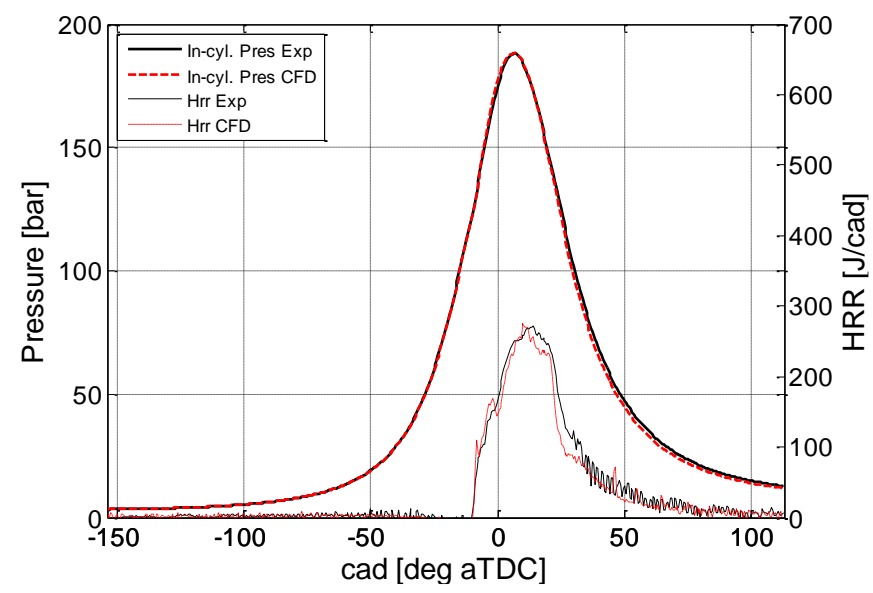



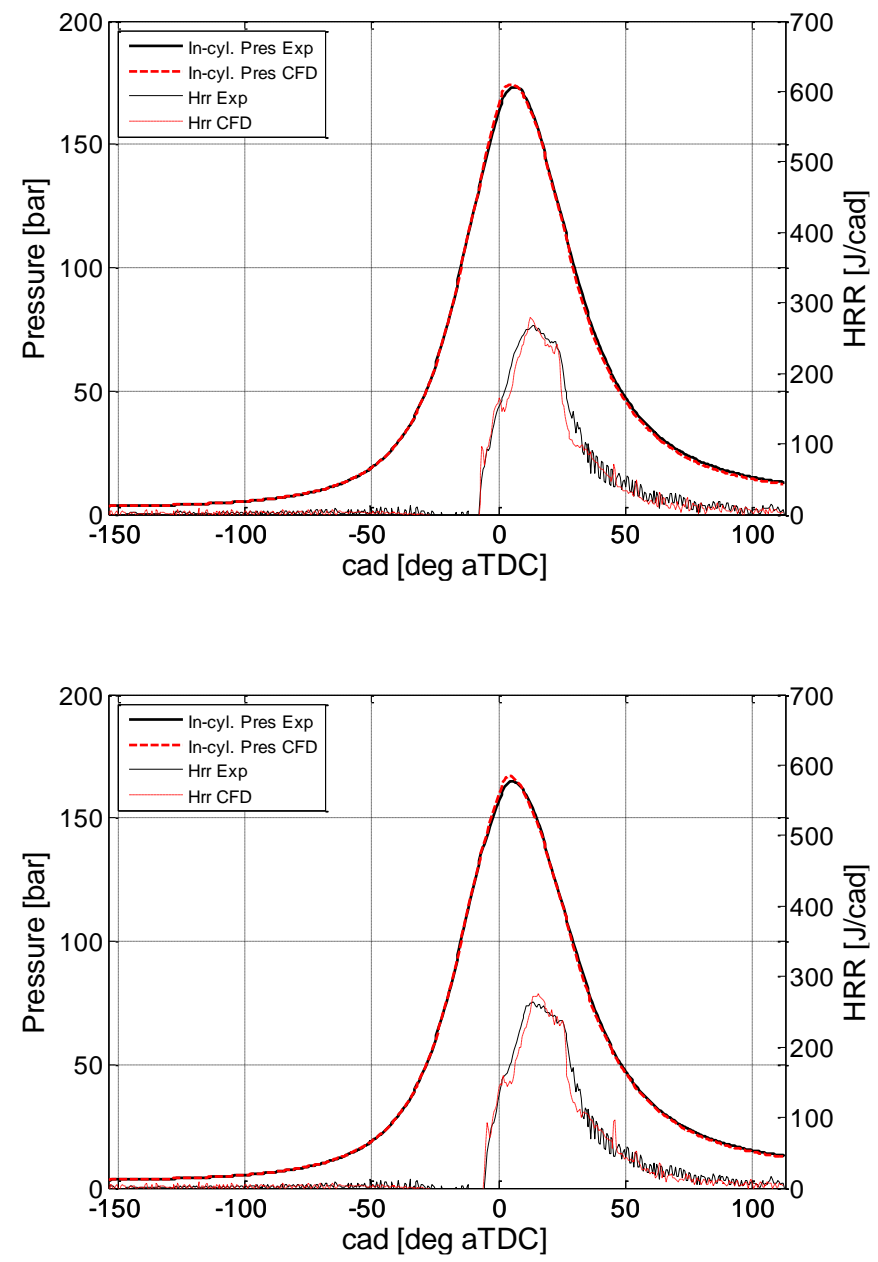

Figure 2 - Comparison of Pcyl and HRR between CFD and experiments at (up) SOI -13 cad, (middle) SOI -10 cad and (bottom) SOI -8 cad.

Table 3 compares the experimental and modeling results in terms of gross indicated efficiency (GIE), maximum pressure rise rate, NOx emissions and peak pressure. In general, it is shown that the experimental results agree with the simulations adequately. The NOx emissions are slightly over predicted by the simulations; however, since the trends are captured accurately, the results are deemed acceptable. Additionally, the CFD results show lower IMEP and GIE values mainly due to the pressure evolution during the expansion stroke, where it is under predicted in all 3 cases. This drop in the cylinder pressure results from the differences in HRR 
observed in all 3 cases around $27 \mathrm{deg}$. After Top Dead Center (ATDC), as the CFD results show a sudden HRR decrease while the experimental results do not show this effect.

Table 3 - Comparison of the selected key parameters between experiments and CFD results with diesel.

\begin{tabular}{|l|l|l|l|l|l|}
\hline \multirow{2}{*}{ Case } & GIE & maxPRR & NOx & PP \\
\cline { 3 - 6 } & {$[\%]$} & {$[$ bar/deg] } & {$[\mathrm{g} / \mathrm{kWh}]$} & {$[\mathrm{bar}]$} \\
\hline \multirow{3}{*}{ SOI -13} & Exp & 44.43 & 5.88 & 2.9 & 188.12 \\
\cline { 2 - 6 } & Diesel CFD & 42.48 & 6.19 & 3.28 & 188.16 \\
\hline \multirow{2}{*}{ SOI -10 } & Exp & 43.31 & 4.72 & 2.05 & 173.27 \\
\cline { 2 - 6 } & Diesel CFD & 42.37 & 5.16 & 2.58 & 174.2 \\
\hline \multirow{2}{*}{ SOI -8 } & Exp & 42.3 & 4.7 & 1.66 & 164.75 \\
\cline { 2 - 6 } & Diesel CFD & 42.37 & 4.71 & 2.13 & 166.95 \\
\hline
\end{tabular}

After performing the CFD model validation with diesel fuel, the same model setup was then used to carry out simulations with DME. The quantity of fuel injected was increased by adjusting the nozzle hole size to match the energy injected in the diesel case. The comparison of the pressure and HRR profiles of the CFD results with diesel fuel and DME is shown in Figure 3.

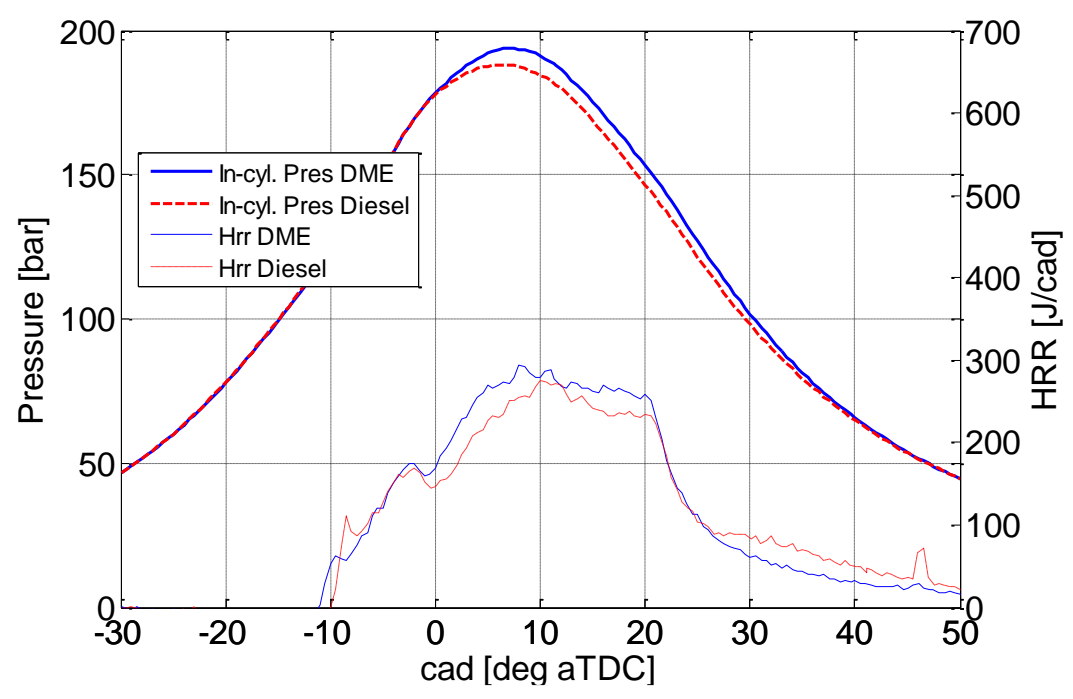

Figure 3 - CFD results of Pcyl and HRR using diesel and DME as fuels. 
Despite not having experimental results operating with DME to compare directly with the modeling results, the main differences between diesel fuel and DME are consistent with those found in the literature. Figure 3 shows a faster heat release rate for DME leading to higher peak pressure and higher gross indicated efficiency, as seen in Table 4. The higher peak pressure and GIE is due to the shorter ignition delay of DME and increased mixing energy resulting from the higher fuel quantity. In relation to NOx emissions, there is some uncertainty since it is not clear if DME levels should be higher or lower than those operating with diesel since there are multiple competing effects [27] [28]; however, the general trends of the model working with DME are similar to the diesel cases, as seen in Table 4. In addition, as reported in the literature carbon monoxide (CO), unburned hydrocarbons (UHC) and soot emissions generated by DME combustion systems are noticeably lower than the diesel values [29], and for this reason they are not considered as restrictions for the optimization so they are not taken into account in the validation process.

Table 4 - Comparison of the restricted parameters and performance between diesel and DME fuels.

\begin{tabular}{|l|l|l|l|l|l|}
\hline \multirow{2}{*}{ Case } & GIE & maxPRR & NOx & PP \\
\cline { 3 - 6 } & {$[\%]$} & {$[\mathrm{bar} / \mathrm{deg}]$} & {$[\mathrm{g} / \mathrm{kWh}]$} & {$[\mathrm{bar}]$} \\
\hline \multirow{2}{*}{ SOI -13 } & Diesel CFD & 42.48 & 6.19 & 3.28 & 188.16 \\
\cline { 2 - 6 } & DME CFD & 42.82 & 6.14 & 2.81 & 193.88 \\
\hline \multirow{2}{*}{ SOI -10 } & Diesel CFD & 42.37 & 5.16 & 2.58 & 174.2 \\
\cline { 2 - 6 } & DME CFD & 42.55 & 5.13 & 2.1 & 177.72 \\
\hline \multirow{2}{*}{ SOI -8 } & Diesel CFD & 42.37 & 4.71 & 2.13 & 166.95 \\
\cline { 2 - 6 } & DME CFD & 42.38 & 4.71 & 1.74 & 168.85 \\
\hline
\end{tabular}

To summarize, the KIVA-3v CFD code was validated against experimental data for diesel fuel and found to yield acceptable results. The previously validated DME reaction mechanism and spray model was used to simulate DME combustion and was shown to follow the general trends discussed in the literature review. Accordingly, it is concluded that the 
integrated CFD model setup is suitable for performing the optimization of the engine combustion system operating with DME.

\subsection{Computational Optimization Details}

\subsubsection{Genetic Algorithm}

The optimization was carried out using an in-house developed genetic algorithm named DKGA. A full description of the DKGA can be found in Klos [30]. The algorithm workflow is described in the 7 steps outlined below:

1. Select the best designs to be the parents for the next generation. For the first generation the parents are the initial conditions provided by the user.

2. Crossbreed the parents using the Punnett square technique (discussed below) to create a new generation.

3. Mutate each chromosome of each child in the generation.

4. Test the population against a fitness function

5. Penalize children that surpass the constraints.

6. Sort the population from highest to lowest.

7. Repeat from step one until the maximum number of generations are complete.

In the present GA, the mating selection is performed by using a Punnett square where the top $n$ designs from the previous generations become the parents of the new generation and each have a child with each other parent twice and themselves once producing a new generation of $n^{2}$ children. After the new generation is created, each variable of each child is then mutated. A normally distributed random number with its mean set to the current value and standard 
deviation set by a decaying time constant is generated and adds mutations to the system. As the GA progresses, the time constant that dictates the mutation rate exponentially decays. The rate at which it decays is defined following

$$
\tau_{G A, i}=\tau_{G A, 0} * \exp \left(-\sigma_{\mathrm{GA}} \frac{i}{n_{\text {end }}}\right)
$$

where $\tau_{G A, i}$ is the time constant at the $i^{\text {th }}$ generation, $\tau_{G A, 0}$ is the user specified initial time constant, $\sigma_{G A}$ is the standard deviation, $n_{e n d}$ is the user specified total number of generations. The decaying time constant enables coverage of the full design space in early generations and forces GA convergence in later generations. This approach has been compared to the micro-GA proposed by Krishnakumar [31] and Senecal [32], the turbo-GA developed by Burjorjee [33], and the non-dominated sorting genetic algorithm (NSGAII) proposed by Deb et al. [34]. In all cases, the current approach resulted in faster convergence. Although many previous engine optimization studies (e.g., Kavuri et al. [35]) have focused on the use of multi-objective optimization tools (e.g., NSGAII) where emissions and fuel consumption are simultaneously minimized. The results of interest are typically minimum fuel consumption subject to emissions and thermomechanical constraints (e.g., peak pressure); accordingly, the use of a single objective optimization with suitable mutation during early generations to fully cover the design space may be a preferable approach. This approach is taken in the present work.

\subsubsection{Piston Bowl Geometry Generation}

A code capable of generating an arbitrarily shaped axisymmetric piston bowl geometry and automatically producing a block structured mesh suitable for KIVA-3v was developed. The code generates the new piston shape and adjusts the clearance height to achieve a target compression ratio. The bowl shape is parametrized by five control points, as shown by p1 to p5 in Figure 4. Each control point is connected by a Bezier spline. 


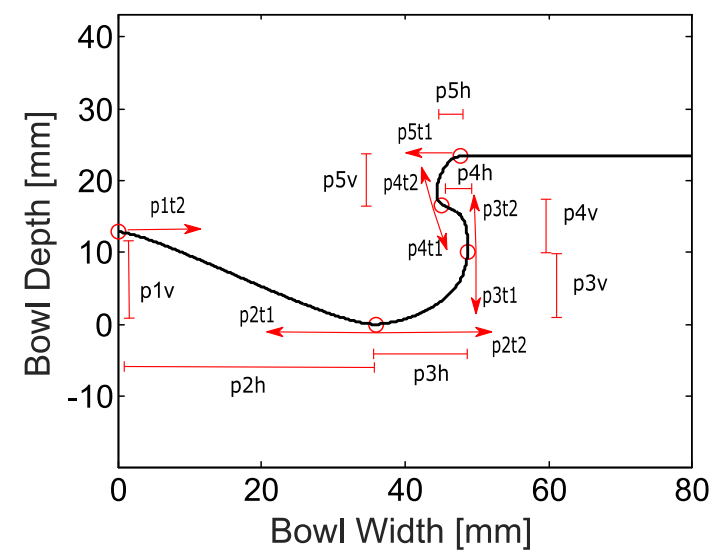

Figure 4 - Distribution of Bezier parameters in the geometry generator tool. The red circles are the control points p1-p5.

In addition to the horizontal and vertical locations of each Bezier point, additional parameters are added to control the slopes and curvatures of the sections between control points. They are represented as 7 inputs in the bowl shape generation, which are able to control the magnitude and orientation of all Bezier curves. After the careful selection of the parameters to identify a compromise between flexibility and optimization expense, a total of 15 inputs were selected to define the bowl geometry, as shown in Figure 5.

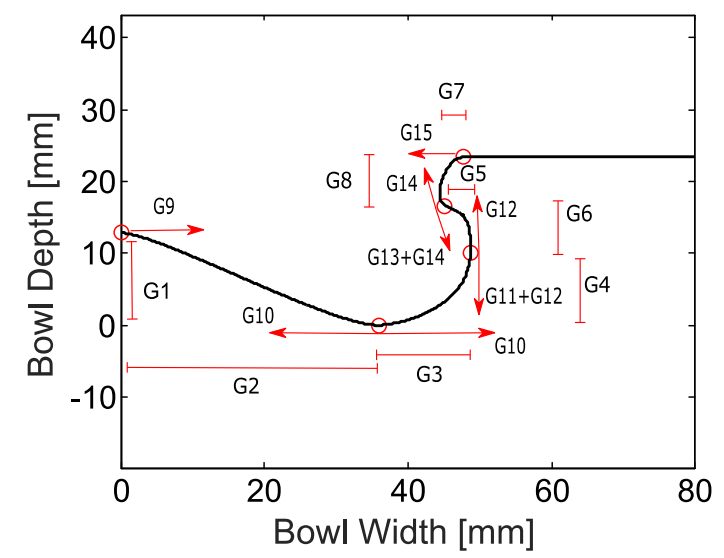

Figure 5 - Optimization parameters related to Bezier geometric points used in the geometry tool.

To illustrate the flexibility of the code, it was used to generate several common piston bowl geometries. The results are shown in Figure 6. 


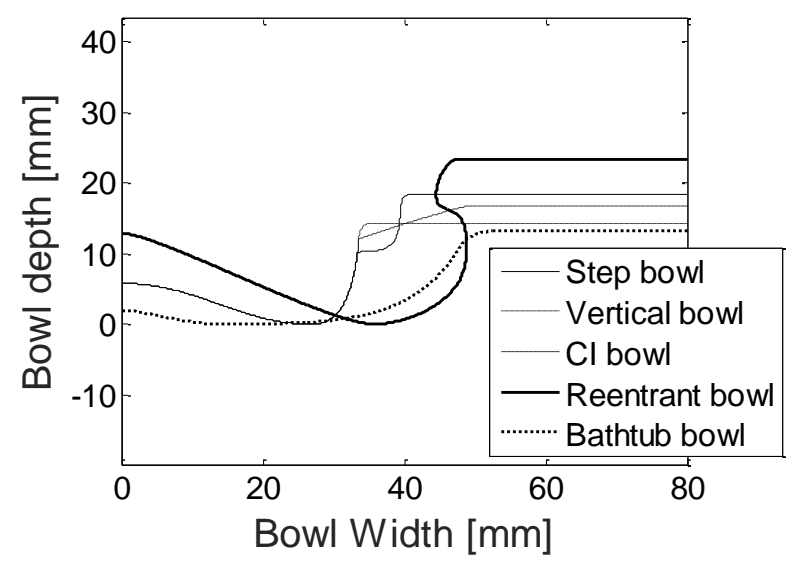

Figure 6 - Example of geometries generated with the geometry generator tool.

\subsubsection{Injection Rate Shape Generation}

The injection rate profile plays a major role in CI engines since it is able to strongly affect their performance and emissions levels. In order to take that into account, an in-house code was developed to automatically generate the injection profile for the different combinations of the two inputs considered in this optimization that affect the injection rate profile, injection pressure and the nozzle hole diameter. A trapezoidal injection rate profile is generated as a function of these two parameters assuming incompressible flow across the nozzle holes and then applying the continuity and the Bernoulli equations between the inlet and outlet of the holes, with a discharge coefficient equal to 0.94 accounting for the flow losses through each hole.

\subsubsection{Optimization Parameters and Setup}

The optimization focused on maximizing net indicated efficiency (NIE) while keeping NOx emissions, peak cylinder pressure (PP), and maximum pressure rise rate (maxPRR) below specified limits. Table 5 summarizes the limits used for each restriction in the optimization. The PP and maxPRR limits were set at 200 bar and 15 bar/deg., respectively. These values were selected to be comparable to a modern heavy-duty engine operating at the rated power condition. The NOx restriction was chosen to be similar to that of a selective catalytic reduction (SCR) catalyst equipped engine designed to meet US2010 emission standards [36]. Soot emissions are 
expected to be negligible for the DME fueled engine; accordingly, no constraint was placed on soot.

Table 5 - Target values used in the optimization for the restrictions.

\begin{tabular}{|l|l|l|}
\hline NOx & PP & maxPRR \\
\hline$[\mathrm{g} / \mathrm{kWh}]$ & {$[\mathrm{bar}]$} & {$[\mathrm{bar} / \mathrm{deg}]$} \\
\hline 2.67 & 200 & 15 \\
\hline
\end{tabular}

The optimization inputs include 15 geometric parameters and 7 injection and air management settings. The 15 geometric parameters are the minimum set required in order to allow the geometric tool to have the freedom to be able to generate any kind of piston bowl geometry. The other 7 inputs were chosen as the most relevant in an internal combustion engine optimization and consist of the start of injection (SOI), exhaust gas recirculation (EGR), pressure at IVC (PIVC), swirl, nozzle hole diameter (dnoz), nozzle half angle (NA) and injection pressure (IP). The ranges of the inputs for the optimization were taken from the limits of current technology and are shown in Table 6.

Table 6 - Intervals used for the optimization parameters and ranges.

\begin{tabular}{|l|c|c|c|c|c|c|c|c|c|c|}
\hline & G1 - G4 & G5 & G6 - G15 & Dnoz & NA & SOI & IP & EGR & PIVC & Swirl \\
\hline & {$[-]$} & {$[-]$} & {$[-]$} & {$[\mathrm{mm}]$} & {$[\mathrm{deg}]$} & {$[\mathrm{cad}]$} & {$[\mathrm{bar}]$} & {$[\%]$} & {$[\mathrm{bar}]$} & {$[-]$} \\
\hline Min. & 0.01 & -0.99 & 0.01 & $2.00 \mathrm{E}-01$ & 45 & -35 & 500 & 2 & 2.5 & 0.1 \\
\hline Max & 0.99 & 0.99 & 0.99 & $3.50 \mathrm{E}-01$ & 90 & 5 & 2600 & 62 & 4 & 3 \\
\hline
\end{tabular}

The optimization process consists of a population of 529 cases per generation with 30 generations having a total of 15,870 function evaluations. The number of function evaluations and generations was based on other similar optimizations carried out previous to this study. 
The optimization results were analyzed using the non-parametric regression model based on the Component Selection and Smoothing Operator (COSSO) method [37], and the low rootmean-square (RSM) error of $0.12 \%$ in NIE assures the quality of the fitting function. With this regression is possible to complete the study by providing not only the optimum values for the inputs, but also the description of the effects of any of the inputs over the optimized NIE. The 15 piston bowl parameters are difficult to interpret; accordingly, they are transformed into 3 new geometric parameters when discussing the results. The new parameters are defined as bowl width, bowl height and K. Revisiting Figure 4, bowl width is defined as the horizontal distance between $\mathrm{p} 5$ and $\mathrm{p} 1$, bowl height as the vertical distance between $\mathrm{p} 5$ and $\mathrm{p} 2$ and $\mathrm{K}$ as the horizontal distance between $\mathrm{p} 4$ and p3 being positive when the bowl has a reentrant shape.

\section{Results and Discussion}

The optimization results are presented and compared to the results using DME in the baseline engine configuration. The parametric effects are then isolated using COSSO to identify key pathways towards a high efficiency DME fueled combustion system.

\section{1. $\quad$ Optimization Results}

Figure 7 shows the evolution of the objective function over for the optimization. The optimum was found after 30 generations and the objective function converged to a NIE value of 49.4\%. The optimum operating parameters for the 22 inputs are shown in Table 7 and Figure 8 compares the optimum geometry for DME with the baseline engine geometry. The optimization process resulted in a wide, shallow piston bowl geometry, compared to the deep, slightly reentrant diesel fuel combustion chamber of the baseline case. The optimized solution uses an injector with 300 micron holes and an included angle of $156^{\circ}$. The start of injection timing is - 
$3.6^{\circ} \mathrm{ATDC}$ and the injection pressure is 2422 bar. The engine uses a relatively high swirl ratio at 2.74 and $30 \%$ EGR.

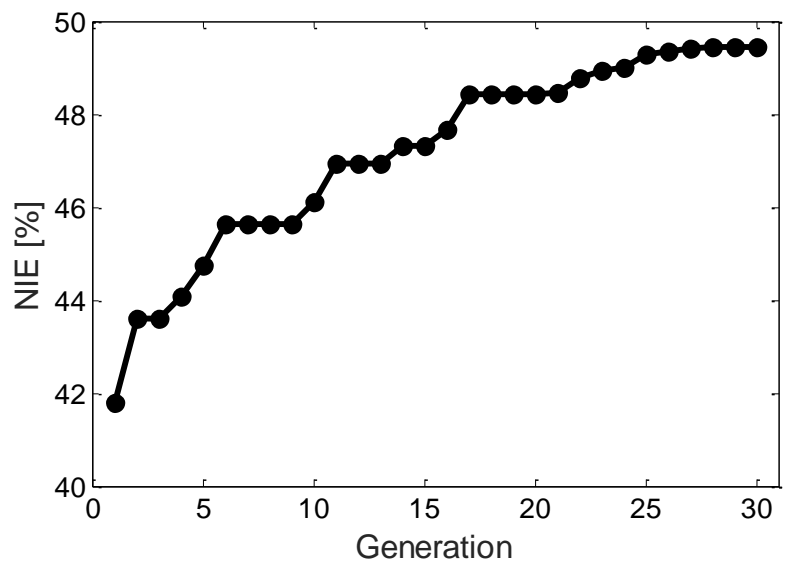

Figure 7 - Optimum objective function value for each generation.

Table 7 - Optimum values for the 22 inputs optimized (top) geometric inputs, (bottom) injection and air management settings.

\begin{tabular}{|l|l|l|l|l|l|l|l|l|l|l|l|l|l|l|}
\hline G1 & G2 & G3 & G4 & G5 & G6 & G7 & G8 & G9 & G10 & G11 & G12 & G13 & G14 & G15 \\
\hline$[-]$ & {$[-]$} & {$[-]$} & {$[-]$} & {$[-]$} & {$[-]$} & {$[-]$} & {$[-]$} & {$[-]$} & {$[-]$} & {$[-]$} & {$[-]$} & {$[-]$} & {$[-]$} & {$[-]$} \\
\hline 0.00 & 0.30 & 0.84 & 0.11 & 0.86 & 0.02 & 0.99 & 0.41 & 0.01 & 0.02 & 0.98 & 0.26 & 0.89 & 0.63 & 0.24 \\
\hline
\end{tabular}

\begin{tabular}{|l|l|l|l|l|l|l|}
\hline Dnoz & NA & SOI & IP & EGR & PIVC & Swirl \\
\hline$[\mathrm{mm}]$ & {$[\mathrm{deg}]$} & {$[\mathrm{cad}]$} & {$[\mathrm{bar}]$} & {$[\%]$} & {$[$ bar $]$} & {$[-]$} \\
\hline 0.3 & 75.94 & -3.58 & 2422 & 30 & 3.48 & 2.74 \\
\hline
\end{tabular}

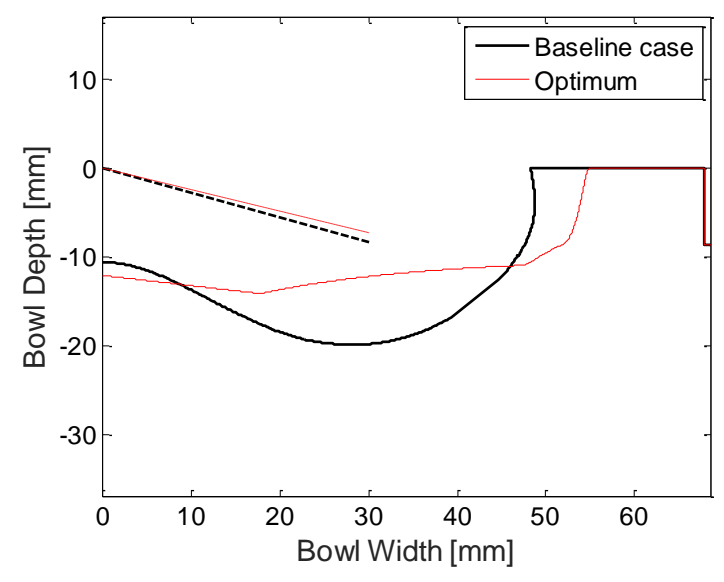

Figure 8 - Optimum and baseline case bowl geometry and nozzle angle configuration. 
Figure 9 shows the results from the optimization as functions of each input variable. The bowl geometry was condensed to the three parameters discussed previously: bowl width, bowl depth, and reentrant factor. Figure 9 shows broad coverage of the design space and convergence to a solution selecting parameters near the peak NIE. The peak NIE of the entire optimization was $50.2 \%$ with a NOx level of $3.75 \mathrm{~g} / \mathrm{kWh}$, maxPRR of $7.9 \mathrm{bar} / \mathrm{deg}$, and peak cylinder pressure of 210 bar. The NOx and peak cylinder pressure of the unconstrained, peak NIE case both exceeded the target values, resulting in reduced merit. The peak NIE case (unconstrained) had a similar, wide, open bowl geometry to that of the constrained optimum solution. The primary difference is a $1.5^{\circ}$ advancement in SOI timing and a 100 bar increase in injection pressure. All other operating parameters are within $3 \%$ of the constrained optimum solution given in Table 7.

The selected bowl geometry is in-line with the expected trend for non-sooting combustion systems where the optimization chooses minimum heat transfer losses. For example, optimization of bowl geometry for Reactivity Controlled Compression Ignition (RCCI), another well-known non-sooting combustion system, resulted in a wide, low surface area piston bowl geometry [38] [39]. Figure 10 shows the NOx and NIE values for all the simulation results with NOx less than the target value. For cases with high NOx levels, the main trend is to converge to a bathtub-type bowl geometry, as proven by the optimum bowl shape provided by the genetic algorithm. However, in order to reach lower NOx values, the optimal geometries tend to move towards reentrant shapes. 

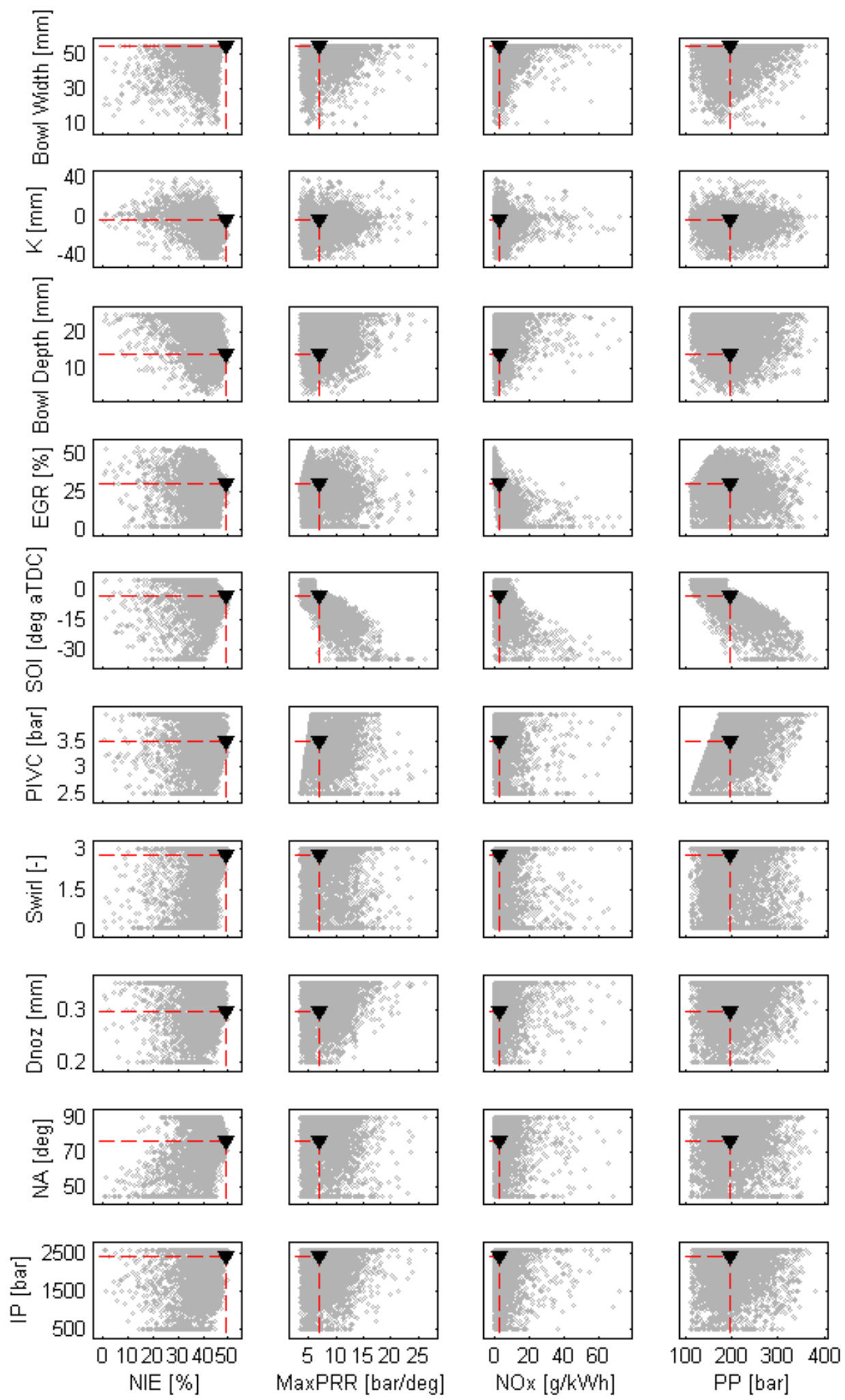

Figure 9 - Input versus output for all optimization cases. All data points are shown in grey circles and the optimum solution is shown by the black triangle. 


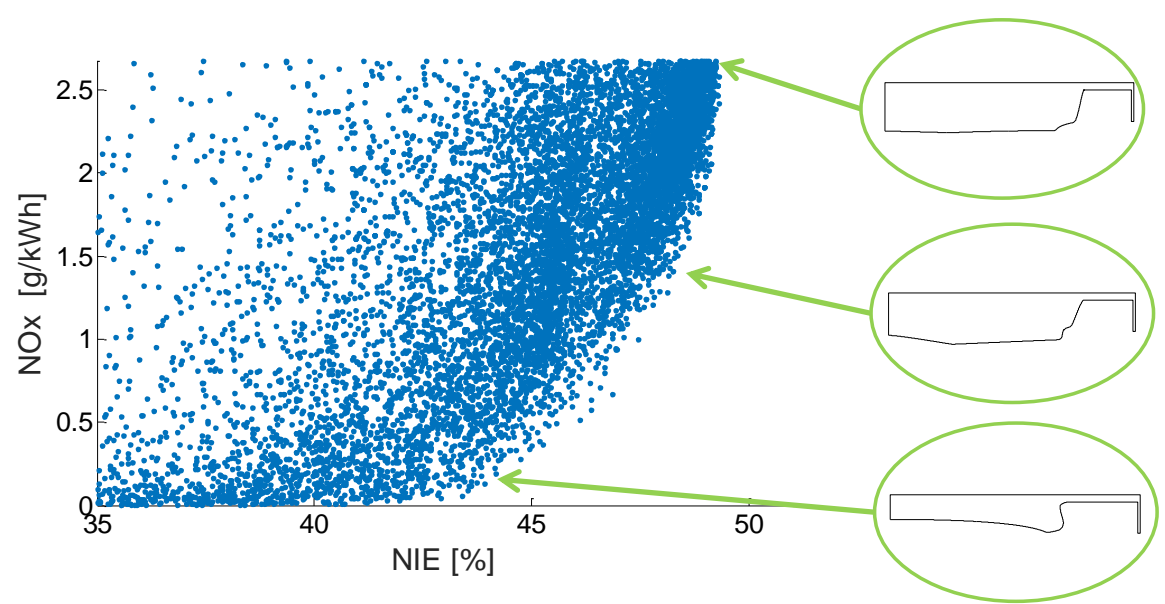

Figure 10 - NOx-NIE trade-off for all the simulated points with NOx levels under the restriction value.

To investigate the impact of the constraints, Figure 11 shows the optimization outputs plotted as functions of each other. These results show that the output space was adequately covered and that allowing operation at higher peak pressure rise rate, higher NOx levels, or higher peak cylinder pressure levels would only enable marginal increases in NIE.
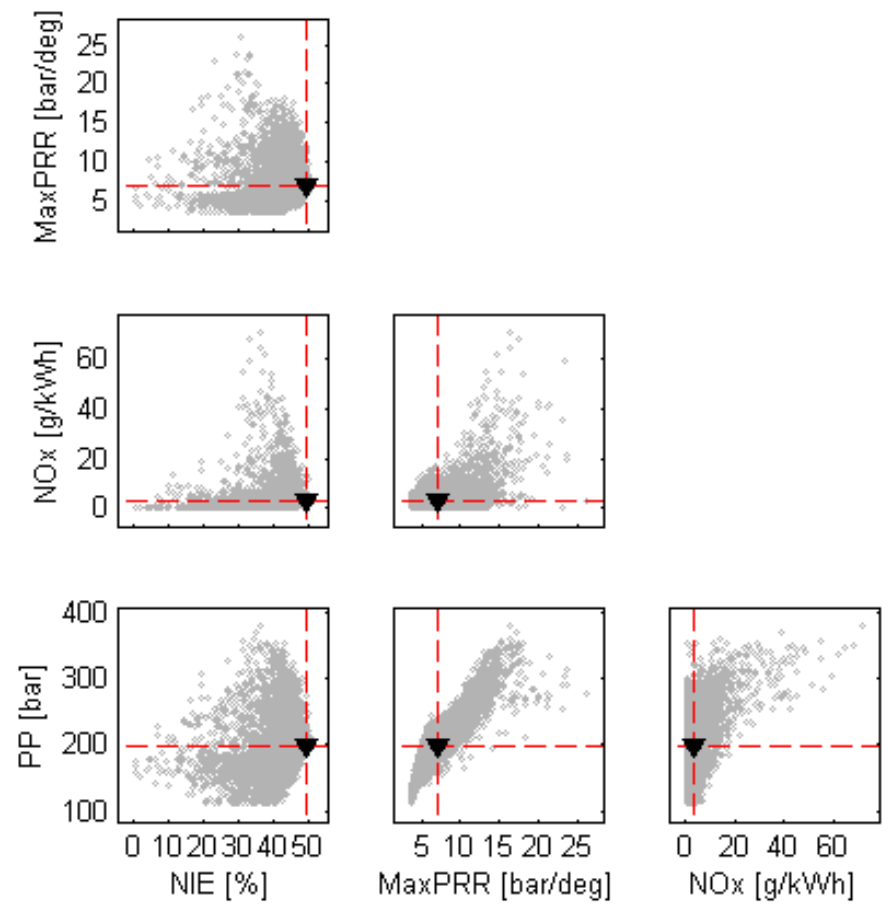

Figure 11 - Output versus output for all optimization cases. All data points are shown in grey circles and the optimum solution is shown by the black triangle. 
The NIE provided by the optimum and the values for NOx, PP and max PRR are shown in Table 8 are compared to the baseline case. The baseline case settings selected corresponds to SOI -13 fueled with DME because it has the best performance of the validated cases and the NOx difference compared with the optimum is the minimum one, so the two combustion systems will be assessed in iso-NOx conditions.

Table 8 - Performance and emissions for the baseline and optimum case.

\begin{tabular}{|l|c|c|c|c|}
\hline Case & NIE & maxPRR & NOx & PP \\
\hline & {$[\%]$} & {$[\mathrm{bar} / \mathrm{deg}]$} & {$[\mathrm{g} / \mathrm{kWh}]$} & {$[\mathrm{bar}]$} \\
\hline Baseline DME case & 42.82 & 6.14 & 2.81 & 193.88 \\
\hline Opt. case & 49.42 & 6.97 & 2.67 & 199.33 \\
\hline
\end{tabular}

The optimum combustion system increased the NIE from the baseline engine fueled with DME $42.8 \%$ up to $49.4 \%$, slightly reducing NOx emissions to fit the requirements and keeping the peak pressure and maxPRR, under the limits.

Figure 12 compares the in-cylinder pressure and HRR of the optimum and the baseline cases. The optimized DME combustion system shows a higher premixed heat release and shorter burn duration. Notice that, although the SOI timing is delayed by 9 degrees, the optimized case is able to end the combustion process earlier than the baseline case as a result of a much faster combustion. The faster combustion results in an increases efficiency as shown in Table 8. 


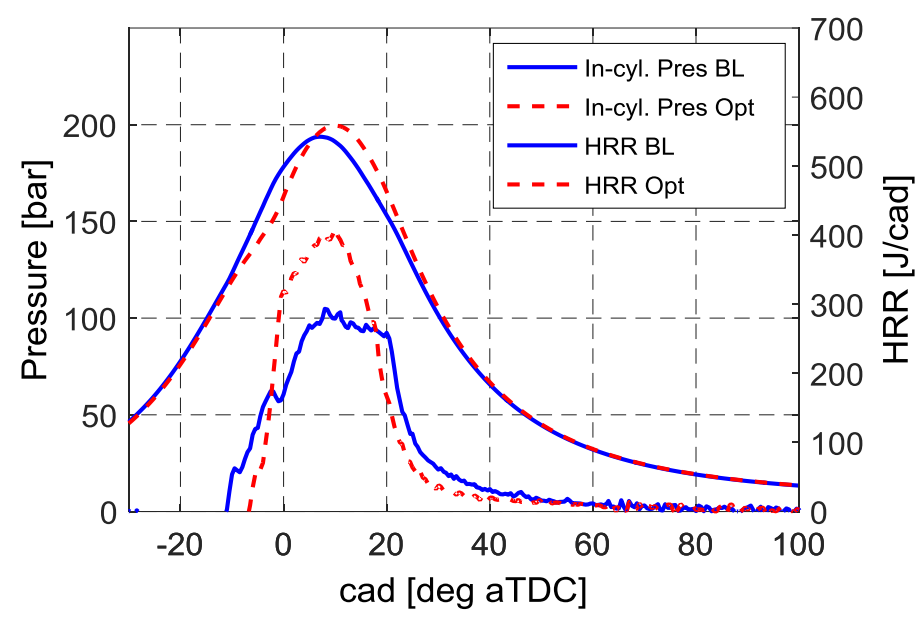

Figure 12 - Comparison of the in-cylinder pressure and HRR for the DME baseline and optimum cases.

To explain the faster combustion, Figure 13 shows the mass of charge in several equivalence ratio ranges for the baseline and optimized cases. It can be seen that the optimized case has a later SOI, but still manages to mix to leaner equivalence ratios earlier than the baseline case, leading to faster combustion as seen in Figure 12. On the contrary, the baseline case is not able to completely burn all the fuel during the combustion process leaving some rich mass in the cylinder at the exhaust valve opening time.

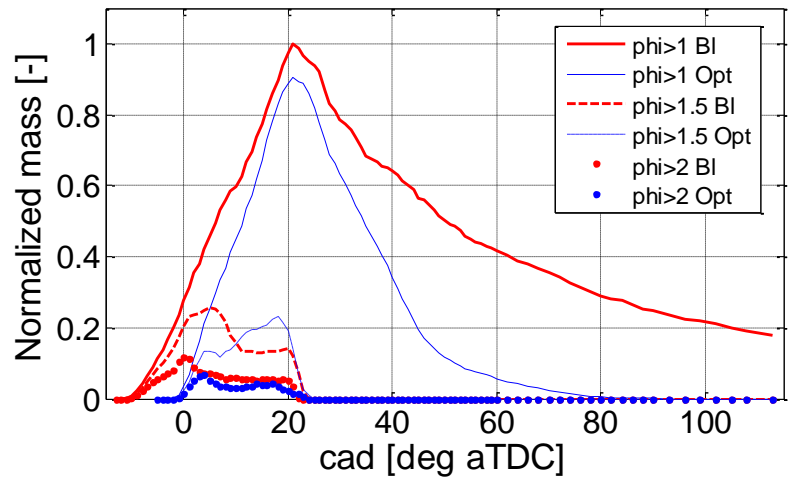

Figure 13 - Comparison between the baseline DME case and the optimum case of the normalized mass with equivalence ratio over $1,1.5$ and 2 .

To further illustrate the differences in mixing leading to a shorter combustion duration for the optimized case, Figure 14 shows equivalence ratio contours for both cases. The baseline case 
is not able to reach the fresh air in the center of the combustion chamber leading to a higher mass with equivalence ratio over 1 . On the contrary, the optimized case shows a more homogeneous mixture and is able to access more of the available fresh air.

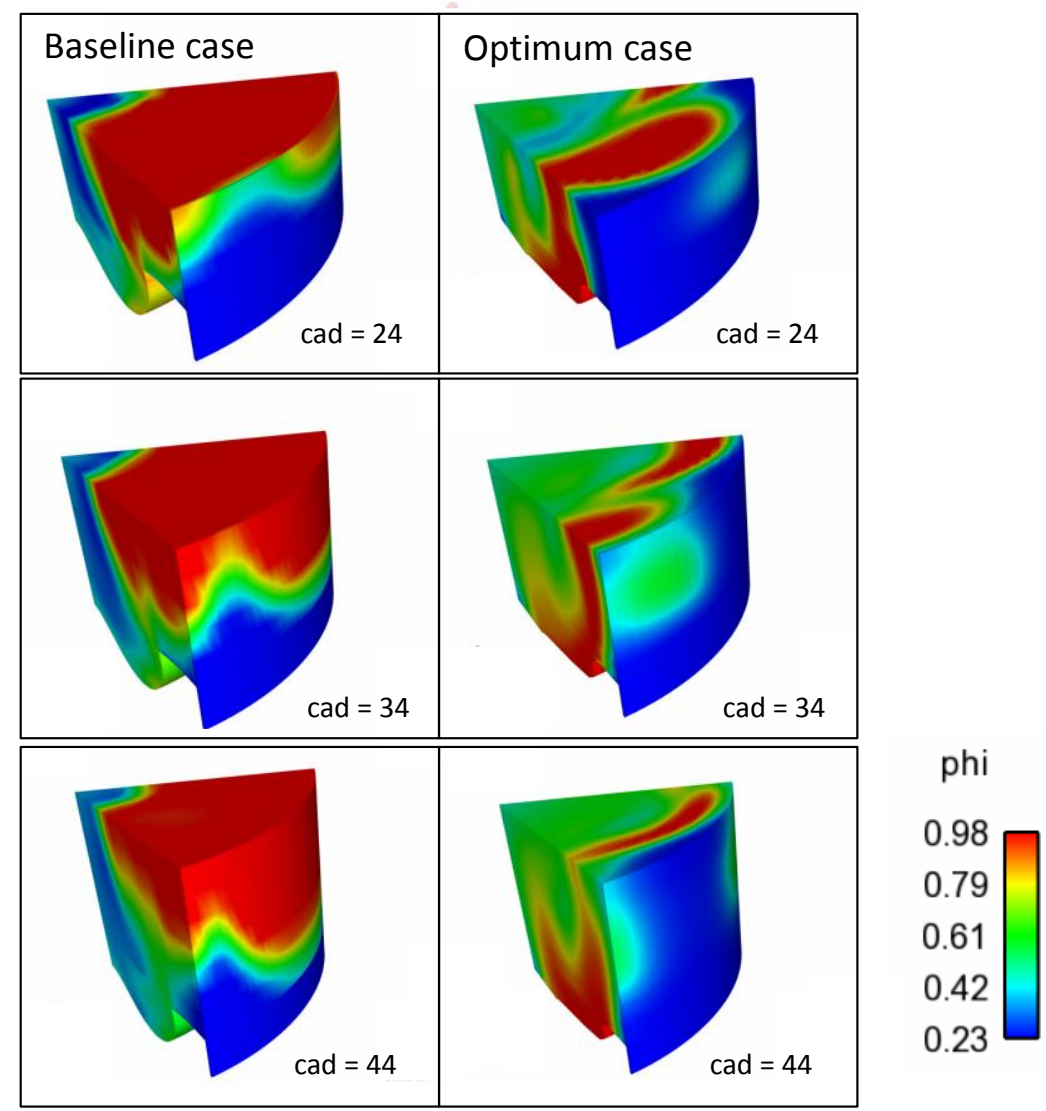

Figure 14 - Phi distribution on (Left column) baseline DME case and (Right column) Opt case.

\subsection{Parametric Dependence}

To gain insight into the parametric dependence of the optimization parameters, the optimization results were analyzed using the non-parametric regression model based on the COSSO method [37]. Figure 15 and Figure 16 show the selected response surfaces of NIE, heat transfer, combustion duration between CA50 - CA10, combustion duration between CA85 CA50, and combustion efficiency. Only the response surfaces of strongly correlated and 
sensitive parameters are presented, while the scales are kept constant for both figures to facilitate the comparison.

Figure 15 shows that the geometry (in this case only bowl width and reentrant parameters) has the potential to improve NIE by up to $4 \%$. This effect can be explained mainly due to 3 phenomena: heat transfer, mixing, and combustion efficiency. In this case the heat transfer shows a strong correlation between the bowl width and reentrant parameter being compulsory to combine wide bowls with top hat shapes or narrow bowls with very flat shapes in order to minimize heat transfer. This effect on heat transfer varies from $1850 \mathrm{~J}$ to $1650 \mathrm{~J}$; however, this can only explain a $1 \%$ NIE variation. That is, heat transfer is not the main factor affected by the geometry. Mixing has been represented by the combustion duration of the early $(\mathrm{CDi}=\mathrm{CA} 50-\mathrm{CA} 10)$ and last $(\mathrm{CDf}=\mathrm{CA} 85-\mathrm{CA} 50)$ portions of the combustion event explaining faster combustion by better mixing. As seen in Figure 15, the effect of the geometry on mixing is almost negligible. Finally the combustion efficiency shows a noticeable dependency on the geometry. The wide bowls, similar to the optimum solution, result in $\sim 5 \%$ increase in combustion efficiency over the narrow geometry. Accordingly, the primary impact of bowl geometry is on combustion efficiency and heat transfer, with only a small effect on mixing. 

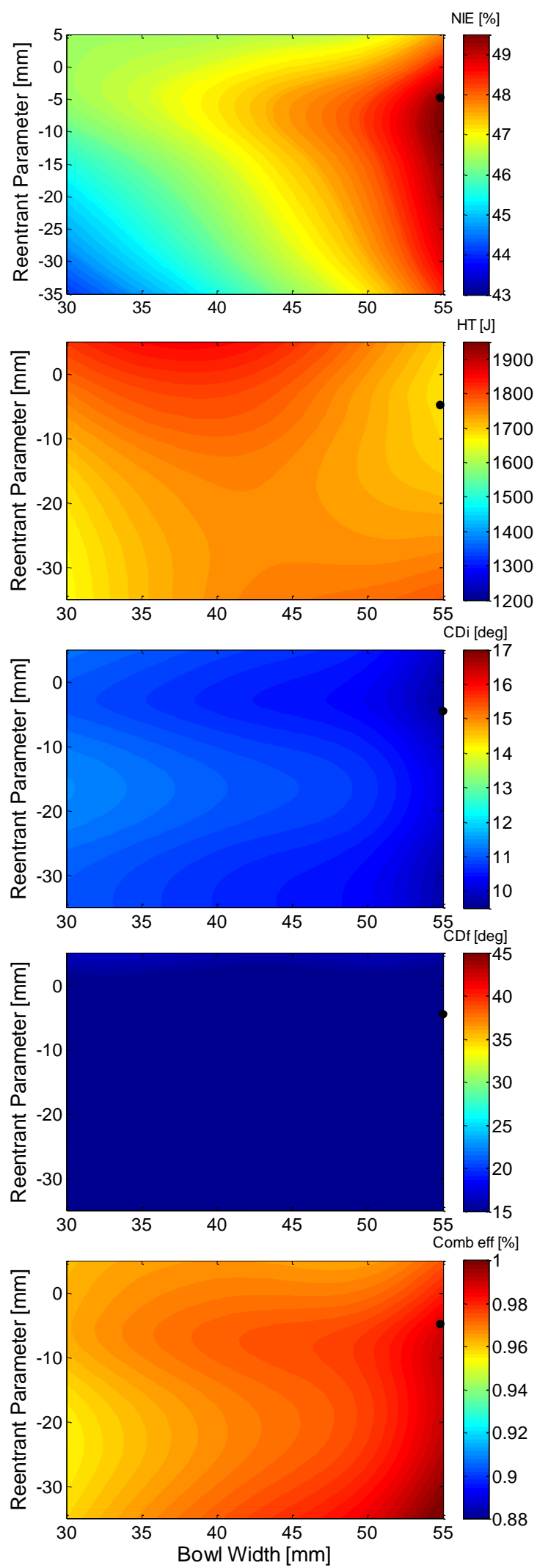

Figure 15 - Response surface of (a) NIE, (b) heat transfer, (c) CA50-CA10, (d) CA85-CA50 and (e) combustion efficiency function of bowl width and reentrant parameter. The optimum is represented with a black dot in all plots. 
Figure 16 shows that swirl ratio and injection pressure have a strong impact on NIE. The optimum solution uses a high swirl ratio and high injection pressure. At a fixed swirl ratio, increasing the injection pressure from 1000 bar to 2500 bar, increases the NIE by approximately $2 \%$ of the fuel energy. Similarly, at a fixed injection pressure, increasing the swirl ratio from 1 to 3 increases the NIE by approximately $4 \%$ of the fuel energy. Higher injection pressure promotes mixing and shortens the combustion duration; however, heat transfer losses also increase due to higher temperatures and higher in-cylinder turbulence levels.

Increasing swirl simultaneously reduces heat transfer and shortens combustion duration. The decreasing combustion duration is expected due to an increase in mixing; however, the heat transfer reduction with increasing swirl ratio was not expected since heat transfer typically increases with increasing swirl ratio. To explain the reduction in heat transfer with increased swirl ratio, CFD results were compared for cases with swirl ratios of 2.74 (optimum) and 2.24 (low swirl optimum). Figure 17 shows temperature contours for these cases. For the case with high swirl, the flame is strongly deflected and it is kept far from the liner wall. When the swirl ratio is reduced, the flame is able to penetrate to the cylinder liner, increasing the temperatures near the liner, and increasing heat transfer losses. Evidently, the primary reason for the heat transfer reduction with increased swirl is that, even though the swirl level increases the local velocities close to the walls and then the local heat transfer coefficients, the higher swirl ratio keeps the flame closer to the center of the combustion chamber, reducing the net heat transfer. 

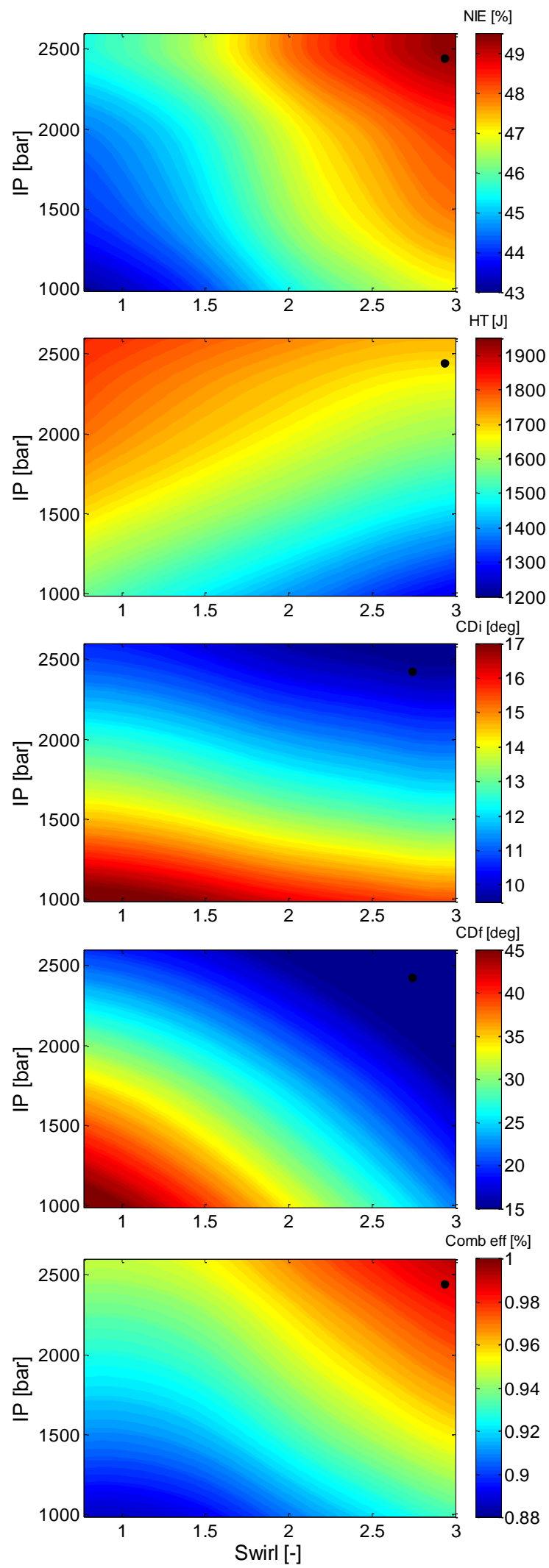

Figure 16 - Response surface of (a) NIE, (b) heat transfer, (c) CA50-CA10, (d) CA85-CA50 and (e) combustion efficiency function of swirl and IP. The optimum is represented with a black dot in all plots. 
Increasing injection pressure and swirl both increase combustion efficiency. The effects of both parameters are similar and complementary. That is, increasing both injection pressure and swirl from the minimum to maximum values increases the combustion efficiency by nearly $12 \%$ of the fuel energy. This appears to be due to improved mixing as evidenced by the similarity between the combustion efficiency contours and the CDf contours. This means that, even though the geometry has a noticeable effect over the combustion efficiency, swirl and IP are the main parameters controlling the mixing and HT, therefore they are the most relevant parameters when optimizing NIE.

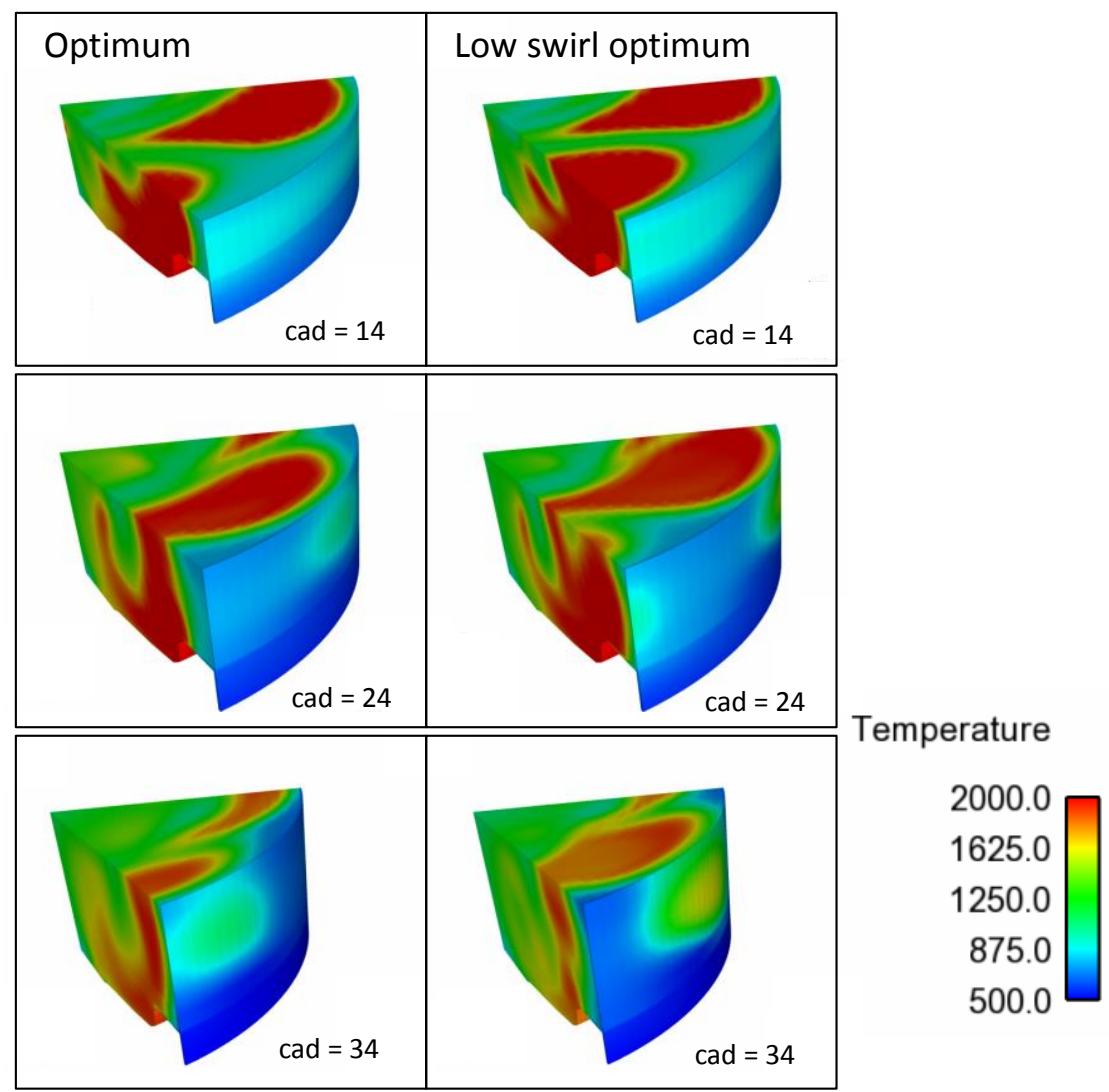

Figure 17 - Temperature distribution on the (Left column) optimum case and (Right column) optimum case with lower swirl. 


\section{Conclusions}

An advanced optimization system has been developed and applied, that not only defines the optimum configuration, but also allows to present the general trends that a non-sooting combustion system requires when working with DME fuel. Also a new bowl geometry generation tool was developed and coupled with the optimization system. It proved to have a wide flexibility being able to generate any type of axisymmetric geometry.

With this system, a computational optimization of DME fueled compression ignition combustion was performed. A total of 22 parameters were optimized (15 geometric, 4 injection settings and 3 air management settings) and an optimum configuration was found with a $6.9 \%$ absolute improvement (15.4\% relative improvement) in NIE over the baseline diesel case with similar NOx emissions, PP and maxPRR levels.

The DME optimum combustion system resulted in a wide, shallow piston bowl geometry, compared to the deep, slightly reentrant diesel fuel combustion chamber of the baseline case. The selected bowl geometry is in-line with the expected trend for non-sooting combustion systems where the optimization chooses minimum heat transfer losses. The optimized solution uses an injector with 300 micron holes and an included angle of $156^{\circ}$. The start of injection timing is $3.6^{\circ} \mathrm{ATDC}$ and the injection pressure is 2422 bar. The engine uses a relatively high swirl ratio at 2.74 and 30\% EGR. The NOx, PP and MaxPRR limits imposed were not too restrictive for the DME fueled engine since the peak NIE case (unconstrained) had a similar geometry and settings configuration than the optimum. Only a small variation of SOI and IP was needed to properly modify the peak NIE case to become the optimum.

The combined effects of optimized parameters on NIE were presented. The effects of swirl and IP were found to be the most relevant. High swirl and IP improve NIE substantially 
since swirl improves heat transfer and end of combustion mixing, while IP has a large effect on mixing and combustion efficiency. In this case, high swirl and IP can increase NIE up to a 7\%.

This work showed that DME is a promising fuel for future generation CI engines and provides guidelines to design compression ignition engines fueled with DME or other high cetane, non-sooting fuels. The present results encourage future investigation activities involving DME engine optimization imposing more stringent targets in line with future emission standards.

\section{Acknowledgements}

Authors acknowledge that this work was possible thanks to the Ayuda para la Formación de Profesorado Universitario (FPU 13/02817) belonging to the Subprogramas de Formación y de Movilidad del Ministerio de Educación, Cultura y Deporte from Spain. 


\section{References}

[1] J. Dec, "Advanced compression ignition engines - understanding the in-cylinder processes," Proceedings of the combustion Institute, vol. 32, no. 2, pp. 2727-2742, 2009.

[2] S. Kokjohn, R. Hanson, D. Plitter and R. Reitz, "Experiments and Modeling of Dual-Fuel HCCI and PCCI Combustion Using In-Cylinder Fuel Blending," SAE International Journal Engines, vol. 2, no. 2, pp. 24-39, 2010.

[3] H. Curran, E. Fisher, P. Glaude, N. Marinov, W. Pitz, C. Westbrook, D. Layton, P. Flynn, R. Durrett, A. Loye and O. C. Akinyemi, "Detailed chemical kinetic modeling of diesel combustion with oxygenated fuels," in SAE Technical Paper, 2001.

[4] H. Teng, J. McCandless and J. Schneyer, "Thermochemical characteristics of dimethyl ether-An alternative fuel for compression-ignition engines," in SAE Technical Paper, 2001.

[5] H. Curran, W. Pitz, C. Westbrook, G. Callahan and F. Dryer, "Oxidation of automotive primary reference fuels at elevated pressures.," In Symposium (International) on Combustion, vol. 27, no. 1, pp. 379-387, 1998.

[6] J. Jang, Y. Lee, C. Cho, Y. Woo and C. Bae, "Improvement of DME HCCI engine combustion by direct injection and EGR," Fuel, vol. 113, pp. 617-624, 2013.

[7] J. Hyung and H. Su, "Optimization study on exhaust emissions and fuel consumption in a 
dimethyl ther (DME) fueled diesel engine," Fuel, vol. 182, pp. 541-549, 2016.

[8] S. Park and S. Yoon, "Injection strategy for simultaneous reduction of NOx and soot emissions using two-stage injection in DME fueled engine," Applied energy, vol. 143, pp. 262-270, 2015.

[9] P. Sungwook, "Optimization of combustion chamber geometry and engine operating conditions for compression ignition engines fueled with dimethyl ether," Fuel, vol. 97, pp. $61-71,2012$.

[10] J. Benajes, R. Novella, J. Pastor, A. Hernández-López, M. Hasegawa, N. Tsuji, M. Emi, I. Uehara, J. Martorell and M. Alonso, "Optimization of the combustion system of a medium duty direct injection diesel engine by combining CFD modeling with experimental validation," Energy Conversion and Management, no. 110, pp. 212-229, 2016).

[11] S. Park, "Optimization of combustion chamber geometry and engine operating conditions for compression ignition engines fueled with dimethyl ether," Fuel, no. 97, pp. 61-71, 2012.

[12] D. Wickman, H. Yun and R. Reitz, "Split-spray piston geometry optimized for HSDI diesel engine combustion," in SAE Technical Paper, 2003.

[13] Y. Shi and R. Reitz, "Assessment of optimization methodologies to study the effects of bowl geometry, spray targeting and swirl ratio for a heavy-duty diesel engine operated at high-load," SAE International Journal of Engines, no. 1, pp. 537-557, 2008.

[14] A. Amsden, "KIVA-3V, Release 2, Improvments to KIVA-3V. LA-UR-99-915," 1999. 
[15] J. Beale and R. Reitz, "Modeling Spray Atomization with the Kelvin-Helmholtz/RayleighTaylor Hybrid Model," Atomization and Sprays, vol. 9, pp. 623-650, 1999.

[16] Y. Ra and R. Reitz, "A reduced chemical kinetic model for IC engine combustion simulations with primary reference fuels.," Combustion and Flame, no. 155, pp. 713-738, 2008.

[17] N. Abani, A. Munnannur and R. Reitz, "Reduction of Numerical Parameter Dependencies in Diesel Spray Models," Journal of Engineering for Gas Turbines and Power, vol. 130, 2008.

[18] F. Perini, "Optimally reduced reaction mechanisms for Internal Combustion Engines running on biofuels," Ph.D. Thesis, University of Modena and Reggio Emilia, 2011.

[19] Z. Han and R. Reitz, "Turbulence Modeling of INternal Combustion Engines using RNG ke Models," Combustion Science and Technology, vol. 106, pp. 267-295, 1995.

[20] S. Kokjohn and R. Reitz, "Investigation of the Roles of Flame Propagation, Rurbulent Mixing and Volumetric Heat Release in Conentional and Low Temperature Diesel Combustion," Journal of Engineering for Gas Turbines and Power, no. 133, 2011.

[21] L. Pan, S. Kokjohn and Z. Huang, "Development and validation of a reduced chemical kinetic model for dimethyl ether combustion," Fuel, vol. 160, pp. 165-177, 2015.

[22] J. Abraham, "What Is Adequate Resolution in the Numerical Computation of Transient Jets," SAE International, no. 970051, 1997.

[23] N. Abani, S. Kokjohn, M. Park, S. Bergin, A. Munnannur, W. Ning, Y. Sun and R. Reitz, "An improved Sray MOdel for Reducing Numerical Parameters Dependencies in Diesel 
Engine CFD Simulations," SAE International, no. 2008-01-0970, 2008.

[24] A. Munnannur, "Droplet Collision Modeling In Multi-dimensional Engine Spray Computations," PHD Thesis in Mechanical Engineering, University of Wisconsin-Madison, 2007.

[25] P. O'Rourke and A. Amsden, "A Spray/Wall Interaction Submodel for the KIVA 3 Wall Film Model," SAE 2000-01-0271, 2000.

[26] N. Allen, "High load Reactivity Controlled Compression Ignition (RCCI) Combustion in a Heavy Duty Engine," M.S. Thesis in Mechanical Engineering, University of Wisconsin Madison, 2014.

[27] G. Thomas, B. Feng, A. Veeraragavan, M. Cleary and N. Drinnan, "Emissions from DME combustion in diesel engines and their implications on meeting future emission norms: A review," Fuel Processing Technology, no. 119, pp. 286-304, 2014.

[28] S. Park and C. Lee, "Applicability of dimethyl ether (DME) in a compression ignition engine as an alternative fuel," Energy Conversion and Management, no. 86, pp. 848-863, 2014.

[29] S. Park and C. Lee, "Combustion performance and emission reduction characteristics of automotive DME engine system," Progress in Energy and Combustion Science, vol. 1, no. 39, pp. 147-168, 2013.

[30] D. Klos, "Investigations of Low Temperature Combustion Engine Desing and Combustion Stability," M.S. Thesis in Mechanical Engineering, University of Wisconsin - Madison, 
2015.

[31] K. Krishnakumar, "Micro-Genetic Algorithms for Stationary and Non-Stationary Funtcion Optimization," Intelligent Control and Adaptive Systems, no. 1196, 1989.

[32] P. Senecal, "Development of a Methodology for Internal Combustion Engine Design Using Multi-Dimensional Modeling With Validation Through Experiments," University of Wisconsin-Madison PhD Theis, 2000.

[33] K. Burjorjee, "Generative Fixation, A unified Explanation for the Adaptive Capacity of Simple Recmbinative Genetic Algorithms," Brandeis University Michtom School of Computer Science, 2009.

[34] K. Deb, A. Pratap, S. Agarwal and T. Meyarivan, "A fast and elitist multiobjective genetic algorithm: NSGA-II," IEEE Transaction on Evolutionary Computation, vol. 6, no. 2, pp. $181-197,2002$.

[35] C. Kavuri, D. Klos, S. Kokjohn and D. Hou, "Blending the Benefits of Reactivity Controlled Compression Igntion and Gasoline Compression Ignition Combustion using an Adaptive Fuel Injection System," International Journal of Engine Research, 2015 (Accepted).

[36] T. Johnson, "Vehicular Emissions in Review," SAE Int. J. Engines, vol. 9, no. 2, pp. 1258$1275,2016$.

[37] Y. Lin and H. Zhang, "Component selection and smoothing in smoothing spline analysis of variance models," Annals of Statistics, vol. 5, no. 34, pp. 2272-2297, 2006. 
[38] S. Molina, A. García, J. Pastor, E. Belarte and I. Balloul, "Operating range extension of RCCI combustion concept from low to full," Applied Energy, no. 143, pp. 211-227, 2015.

[39] S. Kokjohn, R. Hanson, D. Splitter and R. Reitz, "Fuel reactivity controlled compression ignition (RCCI): a pathway to controlled high-efficiency clean combustion.," International Journal of Engine Research, vol. 3, no. 12, pp. 209-226, 2011. 